\title{
DENGEDE OLMAYAN ŞARTLAR ALTINDA KATI MADDE TAŞINIMININ İKİ BOYUTLU OLARAK SAYISAL İNCELENMESI
}

\author{
(NUMERICAL INVESTIGATION OF TWO DIMENSIONAL SEDIMENT \\ TRANSPORT IN NON-EQUILIBRIUM CONDITIONS)
}

\author{
Amin GHAREHBAGHI ${ }^{1}$, Birol KAYA ${ }^{2}$
}

\begin{abstract}
$\ddot{\mathbf{O Z}}$
Askıda katı madde içeren hareketli tabanlı bir yatakta dengede olmayan şartlar altında taban profilinin değişiminin belirlenmesi için üç bileşenden oluşan iki boyutlu bir model geliştirilmiştir. Birinci bileşen çözüm için düzensiz üçgen ağlar oluşturmaktadır. İkinci bileşen sığ su denklemlerini kullanarak akımı modelleyen hidrodinamik bileşendir. Son bileşen ise tabandaki değişimi ve askıdaki katı madde hareketini hesaplayan morfodinamik bileşendir. Denklemler açık Sonlu Hacimler Yöntemi, Toplam Değişim Azalması şeması kullanılarak çözülmüştür. Ayrıca, daha doğru çözüm elde edebilmek için genel denklemlere iki tane çalkantı modeli eklenmiş̧tir. Geliştirilen modelin sonuçlarını denemek amacıyla iki tane hipotez örnek çözülmüştür. Geliştirilen modelden elde edilen sayısal sonuçlar Flow3D yazılımı sonuçlarıyla karşılaş̧ırılmış ve uyumlu olduğu görülmüştür. Ancak, karışım uzunluğu çalkantı modeli sonuçları eddy viskozitesi modeline göre daha uyumludur.
\end{abstract}

Anahtar Kelimeler: Sonlu Hacimler Yöntemi, Toplam Değişim Azalması Şeması, katı Madde Taşınımı, Çalkantı Modeli, Denge Olmayan Taşınım.

\section{ABSTRACT}

A two-dimensional model, under non equilibrium condition, consists of three components has been developed to determine suspended load over an erodible layer. The first component, prepares unstructured triangular meshes. The second component, employs the shallow water equation system to calculate flow treatment, is hydrodynamic component. The last component, determines suspended sediment and bed deformation, is morphodynamic component. The governing equations solved by explicit Finite volume method and discretized by Total Variation Diminishing scheme. In addition, in order to obtain a more accurate solution, two turbulence models has been adjoined to the governing equation. The numerical results of developed model are compared with the results of Flower 3D software. The model was examined for two hypothetical cases. The acceptable compatibility between numerical results of developed model and Flow3D software had been recognized. However, results of mixing length turbulence model are compatible than eddy viscosity model.

Keywords: Finite Volume Method, Total Variation Diminishing scheme, Sediment Transport, Turbulence model, Non-Equilibrium condition.

\footnotetext{
${ }^{1}$ Dokuz Eyül Üniversitesi, Mühendislik Fakültesi, İnşaat Mühendisliği Bölümü, İZMíR, gharehbaghi.amin@gmail.com, (Sorumlu Yazar)

${ }^{2}$ Dokuz Eyül Üniversitesi, Mühendislik Fakültesi, İnşaat Mühendisliği Bölümü, İZMİR, birol.kaya@deu.edu.tr
} 


\section{GİRIŞ}

"Katı madde taşınımı su yapılarının verimli kullanımı, korunması ve akarsu morfolojisi açısından bilinmesi gereken önemli bir konudur. Buna karşın doğada en zor anlaşılan ve en karmaşık olaylardan birisidir" [1]. Akım denklemleri olarak Navier-Stokes Denklemleri (NSD) veya bu denklemleri daha basit bir hali olan Sığ Su Denklemleri (SSD) kullanılabilmektedir [2]. Su yüzeyi profilinin ve askıdaki ve tabandaki katı madde taşınımınının belirlenebilmesi için birçok deneysel çalışma yürütülmüştür [3 vs.]. Yanı sıra NSD'leri veya SSD'leri kullanılarak sayısal çözümler ile kestirimlerde bulunulmaya çalışılmıştır [ 4 vs.] .

Hesaplamalı akışkan dinamiği problemlerinin çözülmesinde Sonlu Farklar Yöntemi (SFY), Sonlu Elemanlar Yöntemi (SEY) ve Sonlu Hacimler Yöntemi (SHY) gibi sayısal çözüm yöntemleri kullanılabilmektedir. Sayısal çözüm yöntemlerinde en önemli aşamalardan birisi ağ oluşturma aşamasıdır. Düzensiz ve eğrisel geometrilerde, yapılandırılmamış ağ geliştirmek kaçınılmazdır. Yukarıda vurguladığımız üç yöntem arasında, SFY'inde düzensiz a ̆ şebekesi kullanarak çözüm yapmak oldukça zordur. Ayrıca eşit ağ sayısı kullanıldığında diğer iki metod, Son SFY'ine nazaran daha hassas sonuç vermektedir [5]. SEY'inin karmaşık geometrilere uygulanabilmesine rağmen bu yöntem ile denklemleri ayrıklaştırma ve ağ şebekesine uyarlamak zor olduğundan dolayı, akışkanlar mekaniği alanında son yıllarda SHY'e daha çok kullanılmaya başlamıştır. Ayrıca SHY korunum denklemlerin integral şeklini çözerek kütle ve momentum miktarının dengesini koruyabilmektedir.

Bradford ile Sanders değişebilen tabanlar üzerinde SHY yardımıyla sadece su yüzeye profilini kestirebilmek amacıyla iki boyutlu bir model geliştirmişler. Bu modelde Roe yaklaşımı Riemann çözücüsü, monotone upstream şeması ve zaman adımları için belirleyicisidüzeltme yöntemi uygulanmıştır. Artı olarak sayısal kesme hatalarını azaltmak için yeni bi teknik uygulanmıştır [6]. Farsirotou vd. tabandaki değişimi açık kanallarda hesaplayabilmek amacı ile, iki boyut'lu nehir ve sel rejiminde çalışabilen model geliştirmişlerdir. Geliştirilmiş modelde SHY açık şemasını kullanarak düşeyde ortalamalı serbest yüzey akış denklemleri ile katı madde taşınımı denklemi aynı anda çözülmüştür [7]. Liu vd. tabandaki oyulmaları hesaplayabilmek için SSD ve katı madde taşınım denklemleri ile iki boyutlu bir model geliştirmişlerdir. $\mathrm{Bu}$ model düzensiz ă̆ sistemini kullanarak SHY ile denklemleri çözmektedir. $\mathrm{Bu}$ çözümlerde Godunov şeması uygulanmıştır. Ayrıca viskoz akımlar için Roe's yaklaşımlı Riemann solver uygulanmıştır [8]. Castro vd. iki boyutlu olarak su yüzeyi profili ile katı madde taşınımını birlikte modellemeye çalışmışlardır. Bu araştırmada su yüzeyi profilini modellemek amacı ile SSD ve katı maddenin taşınımını modelleyebilmek için hidrodinamik değerlere bağlı olan bir katı madde taşınım denklemini kullanmışlardır. Bu çalışmada denklemleri ayrıklaştırabilmek için birinci dereceden Roe-tipi ağ ile yeniden yapılanmış yeni MUSCL-tipi (Monotonic Upstream-Centered Scheme for Conservation Laws) ağı düzensiz ağlar üzerine uygulamışlardır. Ayrıca ikinci dereceden Toplam Değişim Azalması (TDA) Runge-Kutta metodu kullanılmıştır [9]. Kuang vd. su yüzeyi profilini ve tabandaki değişimi iki boyutlu olarak düzensiz üçgen ağlar yardımı ile hesaplaya bilmek için bir model geliştimişlerdir. Bu modelin geliştirmesinde düzensiz SWAN modeli, yarı-kapalı Eulerian-Lagrangian yöntemi, CurWaC2D-Sed ve SHY'den yaralanmışlardır [10]. Cea ile Vázquez-Cendón iki boyutlu bir model geliştirerek yatak sürtünme teriminin ayrıklaştırmasını araştırmışlardır. Yazarlar bu çalışma kapsamında yeni bir düzensiz geriye doğru fark ayrıklaştırma yöntemini bu terim için geliştirmişlerdir [11]. Wu vd. kıyı girişlerde dalgaların etkisinden dolayı katı madde taşınımı ve tabandaki değişimi iki boyutlu olarak 
modellemeye çalışmişlardır. $\mathrm{Bu}$ araştırmada önemli olan kısımlarda daha ince ağ oluşturabilmek için dörtgen biçimli Quadtree ağ yöntemi uygulanmıştır. Ayrıca SIMPLEC (Semi-Implicit Method for Pressure Linked Equations-Consistent) çözüm yolu ve Rhie ile Chow'un momentum enterpolasyon yöntemi (momentum interpolation method) de kullanılmıştır [12]. Gharehbaghi ile Kaya denge durumu için su yüzeyi profilini ve tabandaki değişimi iki boyutlu olarak incelemişlerdir. Bu çalışmada denklemler SHY açık TDA şeması kullanılarak çözülmüştür [13].

$\mathrm{Bu}$ çalışmanın temel amacı dengede olmayan taşınım durumu için kararsız akım koşullarında açık kanallarda su yüzeyi profili, askıdaki katı madde taşınımı ve tabandaki değişimi belirlemek için iki boyutlu bir model geliştirmektir. $\mathrm{Bu}$ alanda geliştirilmiş modellerin çoğu çalkantı terimlerini göz ardı etmektedir. Bu çalışmada, iki çalkantı modeli kullanılmıştır. Geliştirilmiş model ağ, hidrodinamik ve morfodinamik bileşenlerden oluşmaktadır. Ayrıca, SSD'leri ve katı madde taşınımı ile ilgili bazı deneysel denklemler kullanılmaktadır. Son olarak geliştirilmiş modelin sonuçları Flow3D yazılımına karşı test edilmiştir. Flow3D yazılımı son yıllarda yaygın olarak kullanılmaktadır [14-15].

\section{GENEL DENKLEMLER}

$\mathrm{Bu}$ araştırmada su yüzeyi profilini ve katı madde taşınımını hesaplamak için sığ su denklemleri ile deneysel katı madde taşınımı denklemleri uygulanmıştır.

\subsection{Sı ̆̆ Su İle Katı Madde Taşınım Denklemleri}

Karteziyen kordinat sisteminde SSD'leri ve katı madde taşınımı denklemlerinin genel şekli katı madde taşınımının dengede olmadığı durum için iki boyutlu olarak 1-5 denklemlerinde görüldüğü gibi yazılabilir [16].

$\frac{\partial Q}{\partial t}+\frac{\partial F_{x}}{\partial x}+\frac{\partial F_{y}}{\partial y}=S$

$Q=\left[\begin{array}{c}h(1-c) \\ h u \\ h v \\ h c \\ \left(1-p_{s}\right) z\end{array}\right]$

$F_{x}=\left[\begin{array}{c}h u(1-c) \\ \frac{1}{2} g h^{2}+h u^{2}-\frac{h}{\rho_{w}} T_{x x} \\ h u v-\frac{h}{\rho_{w}} T_{y x} \\ h u c \\ \varepsilon q_{b, x}\end{array}\right]$ 


$$
F_{y}=\left[\begin{array}{c}
h v(1-c) \\
h u v-\frac{h}{\rho_{w}} T_{x y} \\
\frac{1}{2} g h^{2}+h v^{2}-\frac{h}{\rho_{w}} T_{y y} \\
h v c \\
\varepsilon q_{b, y}
\end{array}\right]
$$

$$
S=\left[\begin{array}{c}
q_{l w} \\
g h\left(\frac{\partial z}{\partial x}+s_{0 x}\right)-s_{f x}-\frac{\tau_{b x}}{\rho_{w}} \\
g h\left(\frac{\partial z}{\partial y}+s_{0 y}\right)-s_{f y}-\frac{\tau_{b y}}{\rho_{w}} \\
q_{l s u s}+\frac{1}{\rho_{s}}\left[E_{z}-D_{c}\right] \\
\varepsilon\left(q_{l b e d}+\frac{1}{\rho_{s}}\left[D_{c}-E_{z}\right]\right)
\end{array}\right]
$$

Bu denklemlerde; $Q$ zamana göre bileşenlerin türevi, $F_{x}$ ile $F_{y}$ sirası ile bileşenlerin akım ve akıma dik yönlerdeki türevleri, $S$ ise kaynak terimi olmaktadır.

$x$ indisli terimler akım doğrultusundaki, $y$ indisli terimler akıma dik doğrultudaki değerler olmak üzere, $h$ su derinliği, $g$ yerçekimi ivmesi, $z$ tabandaki katı madde yüksekliği, $c$ katı madde konsantrasyonu, $P_{s}$ tabandaki katı maddedinin boşluk oranı, $E_{z}$ ve $D_{c}$ Şekil 1'de görüldüğü gibi sırasıyla tabandan ayrılan ve tabana çökelen katı madde oranlarını, $q_{\text {lsus }}$ yanal askıdaki katı madde, $q_{\text {lbed }}$ yanal tabandaki katı madde, $u$ ile $v$ sirasıly akım ile enkesit yönlerindeki hızları, $\rho_{w}$ ve $\rho_{s}$ sırası ile akışkan ve katı madde yoğunluğu, $S_{0, x}, S_{0, y}$ taban eğimleri, $S_{f, x}, S_{f, y}$ hidrolik eğimleri ve $q_{b, x}, q_{b, y}$ katı madde debilerini, $\tau_{b x}$ ile $\tau_{b y}$ tabandaki kayma gerilmelerini, ve $T_{x x}, T_{x y}, T_{y x}, T_{y y}$ ortalama derinlik çalkantı gerilmelerini göstermektedir. Ayrıca yukarıdaki denklemlerde $\varepsilon=1 /\left(1-P_{s}\right)$ olmaktadır.

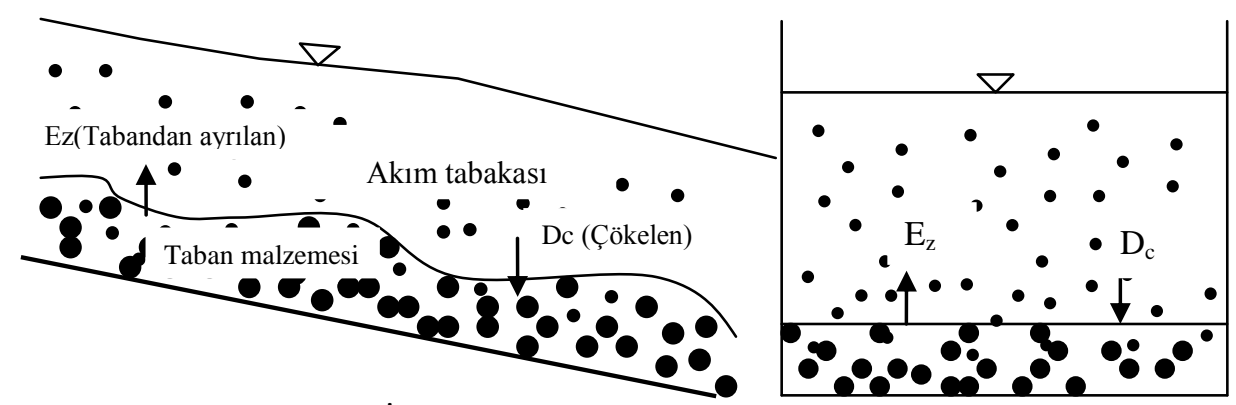

Şekil 1. İki katmanlı sistemin genel görünümü [17]

Tabandaki katı madde taşınımını açık kanallarda ve ırmaklarda hesaplamak amacı ile araştırmacılar tarafından farklı deneysel denklemler geliştirilmiştir. Bu çalışmada farklı araştırmacılar tarafından da kullanılmış olan ve Meyer-Peter-Müller denklemi kullanılmıştır [18]. Dengede olmayan taşınım durumunda çöken ve tabandan ayrılan katı madde miktarına bağlı olarak askıda taşınan madde miktarı konsantrasyon terimi ile ifade edilmektedir. Chien, Meyer-Peter ve Müller’in denklemini aşağıdaki gibi yazılabildiğini göstermiştir [19]. 
$\left\{\begin{array}{l}q_{b, \mathrm{x}}=8 \sqrt{(G-1) g d_{i}^{3}} \frac{u}{\sqrt{u^{2}+v^{2}}} \max \left(\tau_{*}-\tau_{*, c}, 0\right)^{3 / 2} \\ q_{b, \mathrm{y}}=8 \sqrt{(G-1) g d_{i}^{3}} \frac{v}{\sqrt{u^{2}+v^{2}}} \max \left(\tau_{*}-\tau_{*, c}, 0\right)^{3 / 2}\end{array}\right.$

Yukarıda $\tau_{*}$ ile $\tau_{*, c}$ sırası ile katı madde taşınımının kayma gerilmesi ve kritik kayma gerilmeleri $(0,047), d_{i}$ tabandaki katı maddenin ortalama tane çapı ve $G$ katı maddenin yoğunluğunun suyun yoğunluğuna oranı olmaktadır.

\subsection{Dengede Olmayan Durum}

Dengede olmayan katı madde taşınımı durumu için 1-5 nolu temel denklemler verilmiştir. 5. denklemdeki kaynak terimlerinde eğer tabandan ayrılan katı madde $\left(E_{z}\right)$ ile tabana çökelen katı madde $\left(D_{c}\right)$ değerleri eşit alınırsa, denge durumu için denklemler elde edilebilmektedir. Dengede olmayan taşınım durumunda eğer tabandan ayrılan katı madde değeri tabana çökelen katı madde değerinden daha büyükse $\left(E_{z}>D_{c}\right)$ tabandaki katı madde parçacıklarının bir kısmı askıda hareket etmeye başlamış ve konsantrasyon artmıştır. Tabandan ayrılan katı madde değeri tabana çökelen katı madde değerinden daha küçükse $\left(E_{z}<D_{c}\right)$ askıdaki parçacıkların bir kısmı tabana çökelmiş demektir. Bir boyutlu durumda tabandan ayrılan katı madde miktarının $\left(E_{z}\right)$ ve tabana çökelen katı madde miktarının $\left(D_{c}\right)$ değerlerini belirlemek amacıyla, Yang tarafindan bir dizi denklem önerilmiştir [20]. Bu denklemler iki boyutlu akım için geliştirilmiştir.

\section{3. Çalkantı Modelleri}

Hesaplamalı akışkanlar dinamiği alanında su yüzeyi profili, tabandaki değişim ve katı madde taşınımının incelendiği bir çok çalışmada genellikle çalkantı terimleri göz ardı edilmektedir Örnek olarak Liu vd. [8], Castro Diaz vd. [9], Tayfur ile Singh [17], Anastasiou ile Chan [21], vs.). Doğada oluşan çalkantılar akışkanın ve onun içinde harekette olan parçacıkların hareketini etkilemektedir. Çalkantı terimlerinin ihmal edilmesi durumunda hesaplar oldukça kolaylaşmakta, ancak gerçek durumu belirlemekten uzaklaşılmaktadır. Çalkantı terimlerinin genel denklemlere ilave edilmesi durumunda çalkantı kapanış denklemlerinin çözülmesi gerekmekte, ve çözüm zorlaşmaktadır. Ancak daha gerçekçi modeller geliştirilebilmesi, daha güvenilir sonuçlar elde edilebilmesi için çalkantı kapanış denklemlerinin kullanılmasında yarar vardır. Farklı çalkantı modelleri geliştirilmiş olmakla birlikte, bu çalışmada, bu alanda yapılan birkaç çalışmada önerilen derinlik ortalamalı parabolik eddy viskozite çalkantı modeli ve karışım uzunluğu çalkantı modeli kullanılmıştır $[22,23]$. Karışım uzunluğu çalkantı modelinin en önemli özelliklerinden birisi duvara yakın bölgelerde daha hassas çözüm elde edebilmesidir.

\section{SHY ÍLE AYRIKLAȘTIRMA}

Geliştirilmiş iki boyutlu SSD'leri ile katı madde taşınım denklemlerini ayrıklaştırılabilmek için üçgen hücre merkezli SHY uygulanmıştır. Bu ayrıklaştırma düzensiz ăg üzerinde yapılmıştır. Diverjans teoremi uygulanarak 1. denklemi alttaki gibi yazılabilir.

$\iint_{\Omega} \frac{d Q}{d t}+\int_{\partial \Omega} F . n d l=\iint_{\Omega} S d W$ 
Yukarıdaki denklemde $n, d l, d W, \mathrm{~S}$ ve $F$ sırası ile üçgen olarak geliştirilmiş olan ağların dik birim dış vektörü $\partial \Omega$, yay elemanları, alan elemanları, kaynak terimi ve normal akı vektörünü göstermekte ve $F=\left[F_{x}, F_{y}\right]^{T}$ olmaktadır.

Q nun değerinin tüm üçgenlerde sabit ve her üçgenin merkezinde ortalama değerde olduğu düşünülürse bu ifade aşağıdaki gibi yazılabilmektedir.

$\mathrm{A} \frac{d Q}{d t}+\sum_{m=1}^{M} F_{n}^{m} \cdot L^{m}=A S$

Bu denklemde $\mathrm{A}, \mathrm{m}, F_{n}^{m}$, ve $L_{m}$ sirası ile ağlarda oluşturulmuş her bir hücrenin alanını, kenar sayısını, akının hücre kenarlarındaki normali ve her bir hücrenin kenar uzunluklarını göstermektedir. Üçgen ağ alanı şekil 2 de verilmektedir.

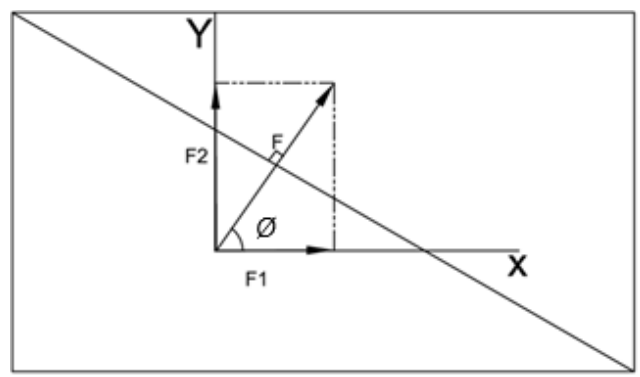

Şekil 2. SHY'nin üçgen ağ alanı

Saatin ibrelerinin tersi yönde $x$ ile $F$ arasındaki açıyı dikkate alarak ve dönme değişmezliğinin uygulanması ile hücrenin her bir yüzeyindeki akının normali alttaki gibi yazılabilir.

$F_{n}(Q)=F_{1} \cos \emptyset+F_{2} \sin \emptyset=T(\varnothing)^{-1} F(\bar{\varnothing})$

$\bar{Q}=\left[\begin{array}{c}h(1-c) \\ h u_{n} \\ h v_{n} \\ h c \\ z\end{array}\right]$

$k_{S}=\varepsilon .8 \sqrt{(G-1) g d_{i}^{3}} \max \left(\tau_{*}-\tau_{*, c}, 0\right)^{3 / 2}$

$F(\bar{Q})=\left[\begin{array}{c}h u_{n} \\ \frac{g h^{2}}{2}+h u_{n}^{2}-\frac{h}{\rho} T_{n n} \\ h u_{n} v_{n}-\frac{h}{\rho} T_{n r} \\ h u_{n} \\ \varepsilon k \frac{u_{n}}{\sqrt{u_{n}^{2}+v_{n}^{2}}}\end{array}\right]$ 
$T(\varnothing)^{-1}=\left[\begin{array}{ccccc}1 & 0 & 0 & 0 & 0 \\ 0 & \cos \emptyset & -\sin \varnothing & 0 & 0 \\ 0 & \sin \varnothing & \cos \varnothing & 0 & 0 \\ 0 & 0 & 0 & 1 & 0 \\ 0 & 0 & 0 & 0 & 1\end{array}\right]$

$$
\begin{array}{ll}
u_{n}=u \cos \emptyset+v \sin \emptyset & v_{n}=v \cos \emptyset-u \sin \emptyset \\
T_{x x}=T_{n n} \cos \emptyset & T_{y y}=T_{n n} \sin \emptyset \\
T_{y x}=T_{n r} \sin \emptyset & T_{x y}=T_{n r} \cos \emptyset
\end{array}
$$

Bu denklemlerde Q'nun hücre yüzeyinin normali doğrultusundaki değeri $\bar{Q}=T(\varnothing) Q$ olmaktadır. $F(\bar{Q})$ akının yüzeyin normali yönündeki değeri, $T(\varnothing)^{-1}$ ters dönüşüm matrisidir. (8) denkleminin bu tanımlara göre düzenlenmesiyle (15) denklemi elde edilmektedir.

$\mathrm{A} \frac{d Q}{d t}+\sum_{m=1}^{M} T(\varnothing)^{-1} F(\bar{Q}) L^{m}=A S$

Bu aşamada en önemli nokta $F(\bar{Q})$ nin hesaplanmasıdır.

\section{TOPLAM DEĞISŞIM AZALMASI ŞEMASI İLE ÇÖZÜM}

Toplam Değişim Azalması (TDA) şemasının kullanılmasının en önemli nedeni zamana bağlı denklemlerin ayrıklaştırılmasında salınımsız çözüm elde etmektir. TDA şeması düzensiz ağ şebekeleri için, $r$ değeri menba yüzeyindeki değişimin mansap yüzeyindeki değişime oranı

$$
r=\frac{\forall_{p}-\forall_{U}}{\forall_{D}-\forall_{p}}
$$

olmak üzere

$\forall_{i}=\forall_{U}+\frac{\psi(r)}{2}\left(\forall_{D}-\forall_{U}\right)$

şeklinde uygulanmaktadır [24]. Burada $\forall_{i}$ kontrol hacminin yüzeyindeki değeri ' $U$ ' ile ' $D$ ' sırası ile memba ile mansap noktalarını göstermektedir.

\section{GELISTTİiLILMIŞ MODELIN UYGULANMASI}

$\mathrm{Bu}$ çalışma kapsamında geliştirilmiş modele denemek amacı ile iki tane farklı hipotez örnek kullanılmıştır.

\section{1. Örnek 1}

Bu örnek için 4 metre uzunluğuna ve 1 metre genişliğinde bir açık kanal düşünülmüştür. Tabanda $3 \mathrm{~cm}$ yüksekliğinde katı madde bulunmaktadır. Tabandaki katı maddenin tane çapları 0,0032 m, boşluk oranı 0,5, manning pürüzlülük katsayısı 0,025 olarak kabul edilmiştir. Ayrıca, kanalın duvarları için manning pürüzlülük katsayısı 0,009 olarak alınmıştır. Bu kanala taban eğimi için akım ile akıma dik yönlerde sırası ile 0,005 ile 0,002 değerleri uygulanmıştır. Kanalın başında akım derinliğinin zamana bağlı olarak değişimi giriş koşulu olarak Şekil 3 de görüldüğü gibi tanımlanmıştır ve girişte enkesit boyunca her noktada aynı değerdedir. Başlangıç şartları olarak akım hızı, akım ve akıma dik doğrultularında sırası ile 
$0,435 \mathrm{~m} / \mathrm{sn}$ ve $0 \mathrm{~m} / \mathrm{sn}$ alınmıştır. Bu örnekte başlangıç anında tüm noktalarda konsantrasyon 0 alınarak temiz su kullanılmıştır.

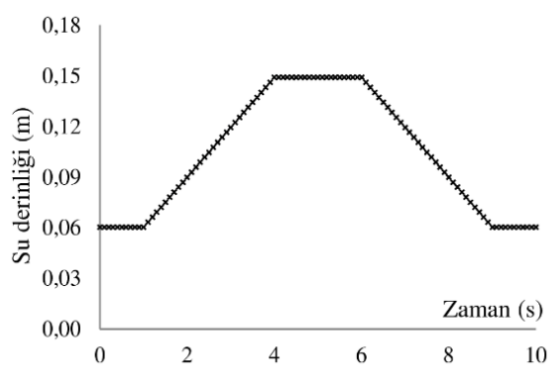

Şekil 3. Giriş Hidrograf

$\mathrm{Su}$ yüzeyi profili ve taban profilindeki değişimler için geliştirilmiş iki boyutlu sayısal model ile elde edilen sonuçlarla Flow3D yazılımı kullanılarak elde edilen sonuçlar, kanalın orta noktasındaki değerler esas alınarak, Şekil 4 ve 5'de verilmiştir. Şekil 4'de t=5sn deki değerler, Şekil 5'de ise t=10sn'deki değerler görülmektedir.

Şekillerde, Flow3D, Flow3D yazılımının hesapladığı su yüzeyi profilinin sonuçlarını, Flow3D.Z, Flow3D yazılımı ile elde edilen taban kotlarındaki değişimi, EVM, yazarlar tarafından geliştirilmiş derinlik ortalamalı eddy viskozite çalkantı modelini kullanan sayısal modelin su yüzeyi profili sonuçlarını, EVM.Z ise taban kotu profili sonuçlarını, MLM, yazarlar tarafından geliştirilmiş karışım uzunluğu çalkantı modelini kullanan sayısal modelin su yüzeyi profili sonuçlarını, MLM.Z ise taban profili sonuçlarını göstermektedir.

Farkl1 2 çalkantı modeli kullanılarak geliştirilen sayısal modellerin sonuçları ile Flow3D yazılımı ile yapılan çözüm sonuçları karşılaştırıldığında, geliştirilen modellerin su yüzeyi profili ve taban profilindeki değișimleri başarılı bir şekilde modelleyebildiği görülmektedir. Dengede olmayan taşınım durumu için yapılan çözümlerde, her iki modelinde kanal başında gözlenen oyulmayı modelleyebildiği ve sonuçların Flow3D sonuçlarıyla uyumlu olduğu söylenebilir. Şekil 5'te görüldüğü gibi MLM yaklaşımında su yüzeyi profilinin küçük bir kısmında sallantılar oluşmuştur. Akışkanlarda çalkantılı durumu modelleyebilmek için bazı kabuller altında farklı yaklaşımlar geliştirilmiştir. Bu modellerin problemlerin çözümündeki davranışları farklı olabilmektedir. Ayrıca kullanılan çalkantı denklemlerinde sonuçları etkileyen bazı sabit değerler ve kabuller yapılması gerekmektedir. Bu çalışmanın sonuçlarına baktığımızda MLM sonuçlarının Flow3D yazılımının sonuçları ile daha uyumlu olduğu söylenebilir.

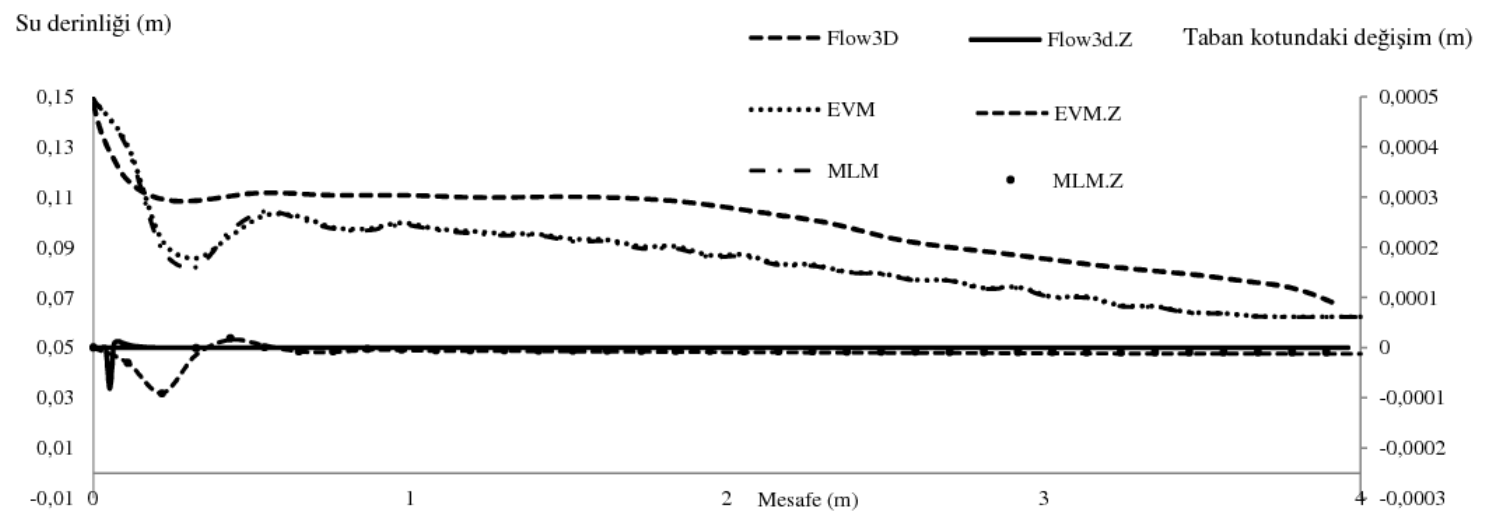

Şekil 4. Kanal boyunca 5. saniyede Flow3D yazılımı, Eddy viskozite modeli (EVM) ve karışım uzunluğu modeli (MLM) ile elde edilen su derinlikleri ve taban kotu değişimleri 


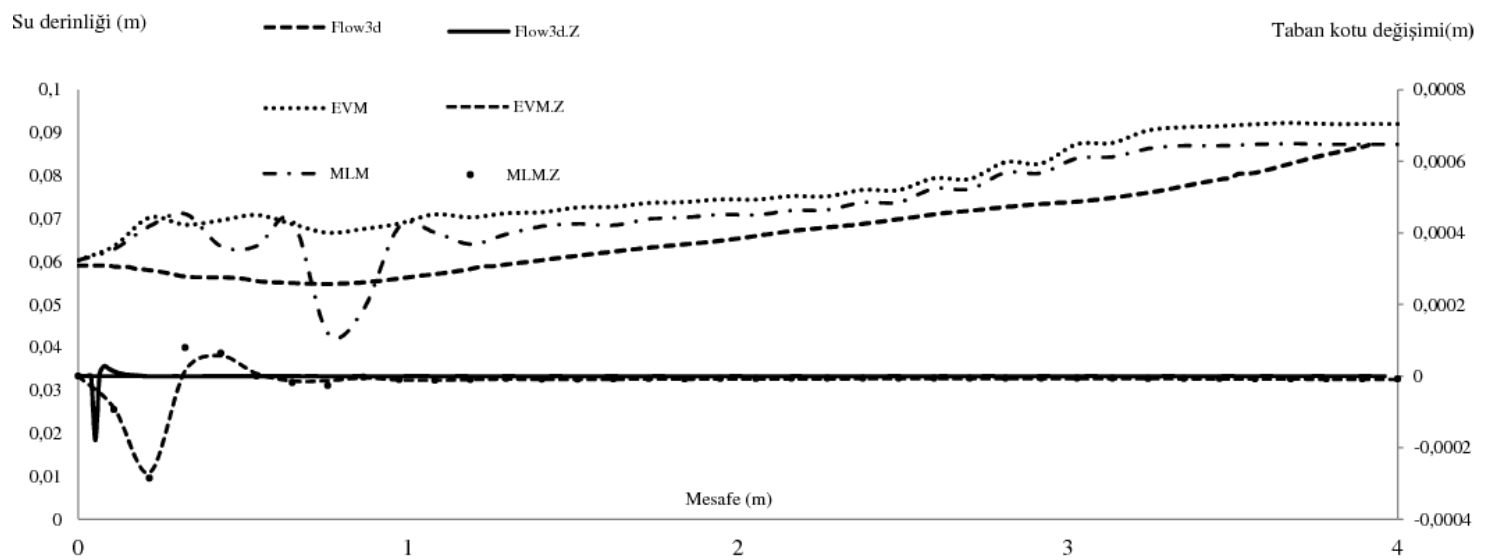

Şekil 5. Kanal boyunca 10. saniyede Flow3D yazılımı, Eddy viskozite modeli (EVM) ve karışım uzunluğu modeli (MLM) ile elde edilen su derinlikleri ve taban kotu değişimleri

Enkesit yönünde sonuçlar birbirine yakın olduğu için, farkların daha iyi anlaşılması amacı ile taban kotlarının Flow3D yazılımı ile elde edilen değerlere göre farkları Flow3D ile elde edilen kot değerlerine bölünerek boyutsuz hale getirilmiştir. Boyutsuzlaştırılmış değerler kanalın birinci metresi için iki farklı zaman diliminde hesaplanmıştır. Boyutsuzlaştırılmış taban kotu farklarının enkesitteki değișimi Șekil 6 ve 7 de verilmiștir.

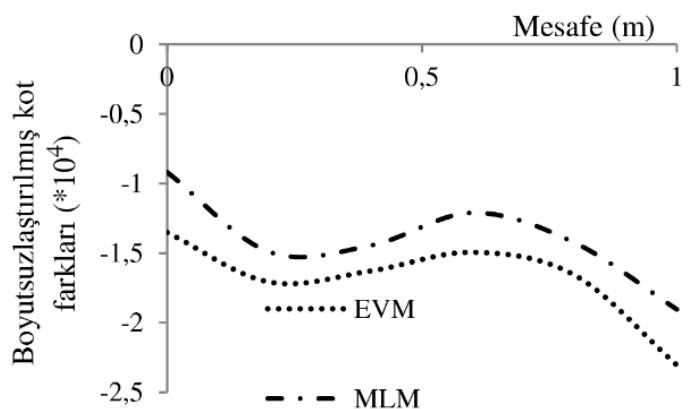

Şekil 6. Kanalın 1. m.’sinde t=5. saniyede boyutsuzlaştırılmış taban kotları farkları

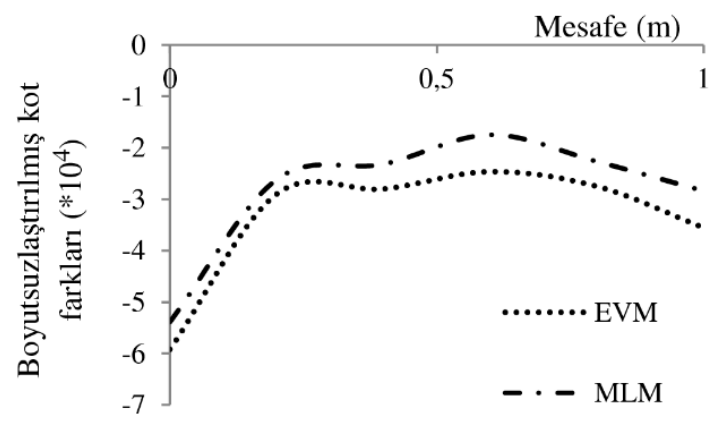

Şekil 7. Kanalın 1. m.'sinde t=10. saniyede boyutsuzlaştırılmış taban kotları farkları

Şekil 6 ve 7 incelendiğinde her iki çalkantı modeli ile elde edilen taban kotlarının Flow3D sonuçlarına oldukça yakın olduğu görülmektedir. İki farklı çalkantı modeli için geliştirilmiş olan sayısal modellerin en önemli özelliklerinden birisi Flow3D yazılımına göre çok daha az ağ sayısı kullanarak Flow3D’ye yakın sonuçların alınabilmesidir. Geliştirilmiş modellerde aynı ağ sayıları kullanılarak çözüm yapılmıştır. Fakat Flow3D yazılımında kararsız çözümler elde edildiğinden daha sık ağ yapısı kullanılmak zorunda kalınmıştır. Her iki model ile elde edilen sonuçlara bakıldığında karışım uzunluğu çalkantı modeli sonuçlarının Flow3D sonuçlarına daha yakın olduğu görülmektedir.

Çalışma süresi bakımından geliştirilmiş modeller ile Flow3D yazılımını karşılaştırdığımızda, Flow3D yazılımının daha kısa bir sürede sonuç verdiği görülmüştür. Geliştirilen modellerde daha az ağ sayısı kullanılmasından dolayı daha kısa sürede sonuç alınması beklenmektedir. İşlem süresinin daha fazla olması hesaplamalar için yazılan bilgisayar programın da işlem sürelerini kısaltacak bazı iyileştirmeler yapılması gerektiğini göstermektedir. 


\section{2. Örnek 2}

İkinci örnek için kanalın boyu $5 \mathrm{~m}$, eni ise 0,8 metre seçilmiştir. Kanalın tabanında $3 \mathrm{~cm}$ kalınlığında katı madde bulunmaktadır. Taban malzemesi için tane büyüklüğü $0,0032 \mathrm{~m}$, boşluk oranı 0,5, manning pürüzlülük katsayısı 0,04 olarak kabul edilmiştir. Ayrıca kanalın yan duvarları için manning pürüzlülük katsayısı 0,009 olarak alınmıştır. Bu kanalda akım doğrultusunda 0,005, akıma dik doğrultuda 0,002 kanal taban eğimi değerleri seçilmiştir. Başlangıçta kanal boyunca akım derinliği $0,1 \mathrm{~m}$, akım doğrultusunda hız 1,044 m/sn ve akıma dik yönde hız $0 \mathrm{~m} / \mathrm{sn}$ olarak alınmıştır.

$\mathrm{Bu}$ örnekte kanalın başında suya katı madde eklenilmiştir. Eklenilen katı maddenin hidrografı Şekil 8'de verilmektedir. Girişteki akım hidrografı ise Şekil 9'da görülmektedir.

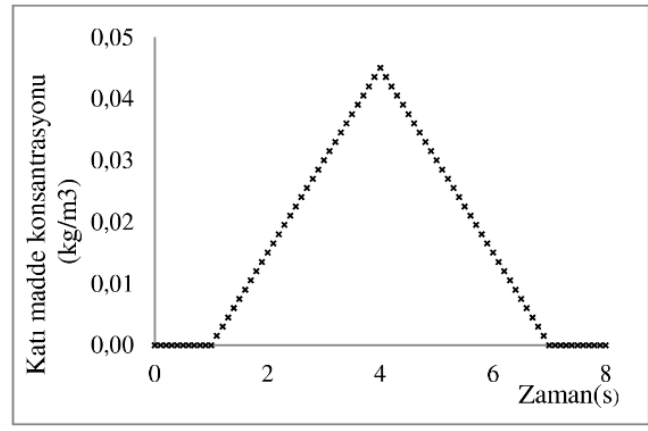

Şekil 8. Katı madde konsantrasyonunun giriş hidrografi

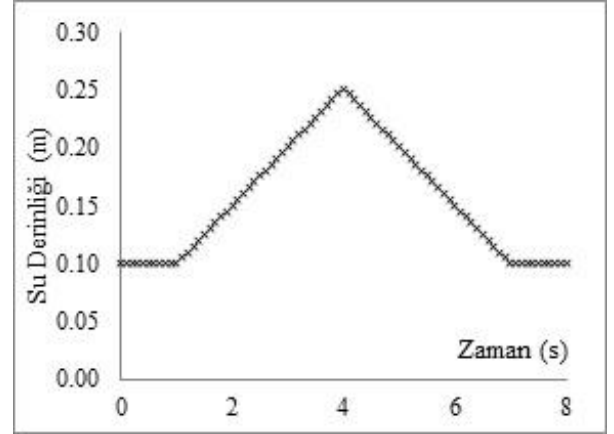

Şekil 9. Akım giriş hidrografı

Verilen koşullarda altında geliştirilmiş sayısal modellerle elde edilen sonuçlara göre, kanal enkesitinin orta noktası için $\mathrm{t}=4$. sn'de görülen su yüzeyi profili ve taban profili Şekil 10'da, $\mathrm{t}=8$. sn'de görülen su yüzeyi profili ve taban profili ise Şekil 11 de verilmiştir. Şekillerden görüldügü gibi her iki çalkantı modeli kullanılarak elde edilen sonuçlar Flow3D sonuçlarıyla uyumludur. Kanalın başlangıç kesiminde Flow3D sonuçlarında görülen oyulmanın, geliştirilen modellerde de gerçekleştiği gözlenmektedir. Oyulmanın miktarı ve konumunda sayısal çözümde kullanılan yöntem, uygulanan yaklaşım, kabuller, ağ sayısı gibi bir çok parametre etkili olmaktadır. Her ne kadar Flow3D uygulamada kullanım alanı bulmuş güvenilir bir program olsa da sayısal sonuçlar deneysel sonuçlarla karşılıştırılarak modelin kalibrasyonunun tamamlanmasında yarar vardır. 


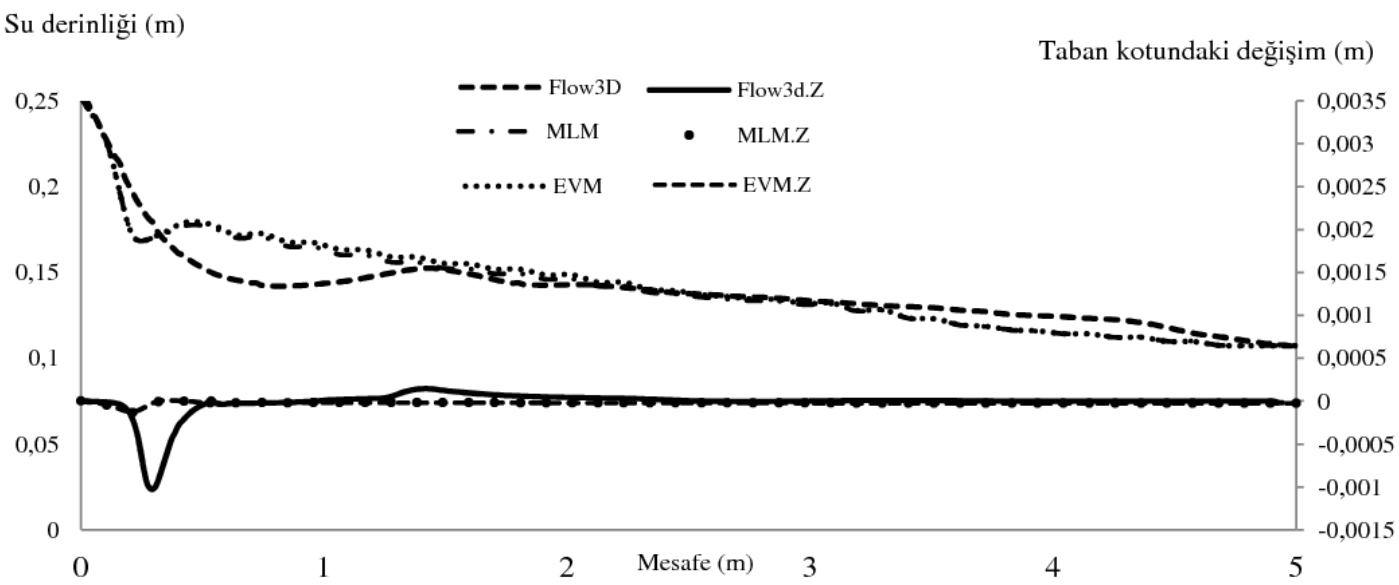

Şekil 10. Kanal boyunca 4. saniyede Flow3D yazılımı, Eddy viskozite modeli (EVM) ve karışım uzunluğu modeli (MLM) ile elde edilen su derinlikleri ve taban kotu değişimleri

$$
\text { Su derinliği (m) } \quad \text { Taban kotundaki değişim (m) }
$$

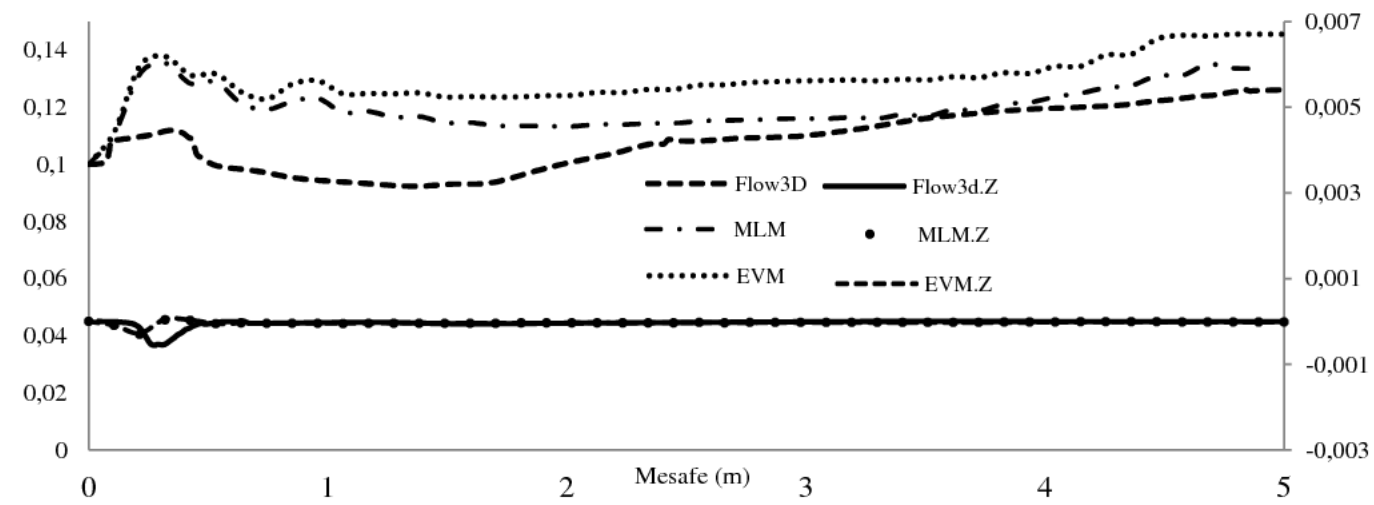

Şekil 11. Kanal boyunca 8. saniyede Flow3D yazılımı, Eddy viskozite modeli (EVM) ve karışım uzunluğu modeli (MLM) ile elde edilen su derinlikleri ve taban kotu değişimleri

Geliştirilen modeller ile elde edilen taban kotlarının Flow3D yazılı ile elde edilen taban kotlarından farklarının enkesitteki değişimleri boyutsuz olarak Şekil 12 ve 13'de verilmiştir. Kanalın 2,5 m'sinde $\mathrm{t}=4$. sn ve $\mathrm{t}=8$. sn için verilen değerler incelendiğinde elde edilen sonuçların Flow3D sonuçları ile uyumlu olduğu görülmektedir. Askıdaki katı madde miktarının kanal boyunca değişimi ise boyutsuz olarak $\mathrm{t}=4$. sn için Şekil $14 \mathrm{de}, \mathrm{t}=6$. sn için ise Şekil 15'de verilmiştir.

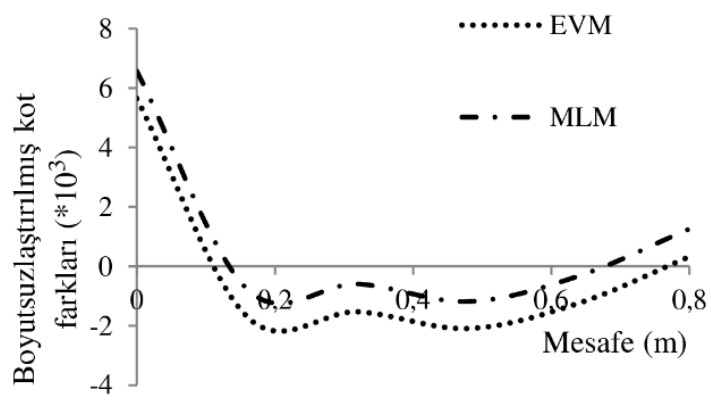

Şekil 12.. Kanalın 2,5. m.'sinde t=4. saniyede boyutsuzlaştırılmış taban kotları farkları

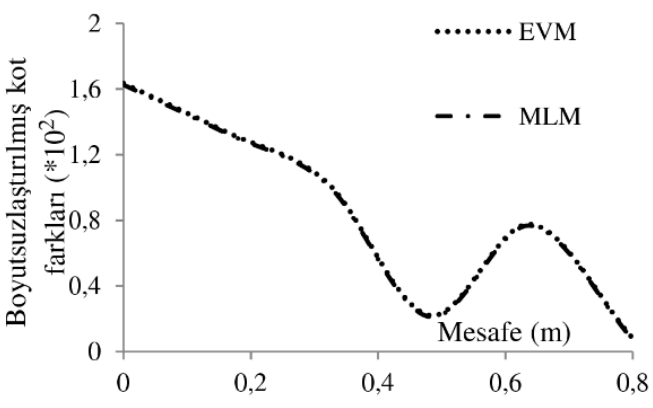

Şekil 13. Kanalın $2.5 \mathrm{~m}$.' sinde $\mathrm{t}=8$. saniyede boyutsuzlaştırılmış taban kotları farkları 



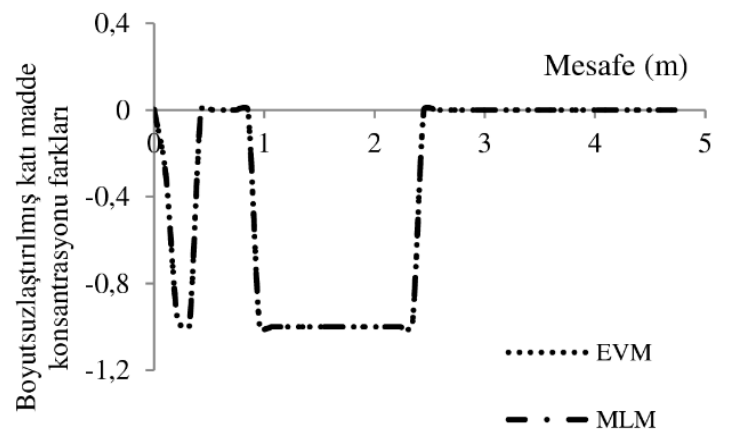

Şekil 14. Kanal boyunca 4. saniyede Boyutsuzlaştırılmış katı madde konsantrasyonu farkları

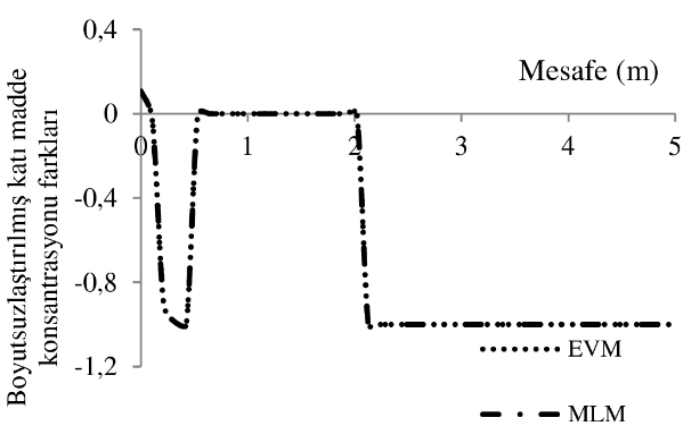

Şekil 15. Kanal boyunca 6. saniyede Boyutsuzlaştırılmış katı madde konsantrasyonu farklar1

İki farklı çalkantı modeli kullanılarak yapılan çözümler ile Flow3D yazılımı ile yapılan çözümler karşılaştırıldığında, gerek su yüzeyi profili, gerek taban profili ve gerekse askıdaki katı maddenin değişiminin, Flow3D yazılımı sonuçlarıyla uyumlu olduğu görülmektedir. $\mathrm{Bu}$ sonuçlar elde edilirken Flow3D yazılımında daha fazla sayıda ağ kullanılmıştır. Çünkü küçük ağ sayılarında Flow3D ile karasız çözümler ortaya çıkmıştır. Çalkantı modellerinin sonuçlarına bakıldığın da, her iki modelinde sonuçlarının Flow3D ile uyumlu olduğu görülse de, karışım uzunluğu modeli kullanılarak elde edilen sonuçların, Flow3D sonuçlarına daha yakın olduğu görülmektedir.

\section{SONUÇLAR}

Bu çalışmada dengede olmayan taşınım durumu için iki farklı çalkantı modeli kullanılarak iki boyutlu modeller geliştirilmiş ve açık kanallarda tabandaki değişim ve askıdaki katı madde hareketi incelenmiştir. Geliştirilen modeller üç bileşenden oluşmaktadır. Birinci bileşen üçgen ağların oluşturulması bileşenidir. İkinci bileşen SSD'leri yardımı ile akım parametrelerinin hesaplandığı bileşendir. Son bileşen ise katı madde taşınımını hesaplamaktadır. Denklemlerin ayrıklaştırması için açık SHY kullanılmıştır. SHY'iyle çözümde TDA şeması kullanılmıştır.

Derinlik ortalamalı eddy viskozite çalkantı modeli ile karışım uzunluğu çalkantı modelinin kullanıldığı iki sayısal model ile su yüzeyi profilinin değişimi, taban profilinin değişimi ve askıdaki katı madde konsantrasyonunun değişimi incelenmiş ve elde edilen sonuçların Flow3D yazılımı sonuçlarıyla uyumlu olduğu görülmüştür. Ancak karışım uzunluğu çalkantı modelinin kullanıldığı sayısal model sonuçları Flow3D sonuçlarına biraz daha yakın olarak elde edilmiştir.

Geliştirilen modeller kullanılarak elde edilen sayısal sonuçlar, uygulama kullanım alanı bulmuş, güvenilir bir program olan Flow3D sonuçları ile karşılaştırılmıştır. Ancak Flow3D programı da bir takım kabul ve yaklaşımlar altında sayısal çözüm yapmaktadır ve gerçek durumu birebir modellemesi beklenemez. Dolayısıyla model sonuçlarının deneysel sonuçlarla karşılaştırılması daha sağlıklı olacaktır. 


\section{SEMBOLLER}

$Q$ zamana göre bileșenlerin türevidir

$F_{x}$ ile $F_{y}$ sırası ile bileşenlerin akım ve akıma dik yönlerdeki türevleridir.

$S$ kaynak terimi,

$h$ su derinliği,

$g$ yerçekimi ivmesi,

$z$ tabandaki katı madde yüksekliği,

$P_{s}$ tabandaki katı maddedinin boşluk oranı,

$E_{z}$ ve $D_{c}$ sırasıyla tabandan ayrılan ve tabana çökelen katı madde oranlarını,

$q_{\text {lsus }}$ ve $q_{\text {lbed }}$ sırasıyla yanal askıdaki katı madde ve yanal tabandaki katı madde,

$u$ ile $v$ sırası ile akım ile enkesit yönlerindeki hızları,

$\rho_{w}$ ve $\rho_{s}$ sırası ile akışkan ve katı madde yoğunluğu

$S_{0, x}, S_{0, y}$ sırası ile akım ile enkesit yönlerindeki taban eğimleri

$S_{f, x}, S_{f, y}$ sırası ile akım ile enkesit yönlerindeki hidrolik eğimleri

$q_{b, x}, q_{b, y}$ sırası ile akım ile enkesit yönlerindeki katı madde debileri,

$\tau_{b x}$ ile $\tau_{b y}$ sirası ile akım ile enkesit yönlerindeki tabandaki kayma gerilmeleri,

$T_{x x}, T_{x y}, T_{y x}, T_{y y}$ ortalama derinlik çalkantı gerilmeleri

$\tau_{*}$ ile $\tau_{*, c}$ sırası ile katı madde taşınımının kayma gerilmesi ve kritik kayma gerilmeleri

$d_{i}$ tabandaki katı maddenin ortalama tane çapı

$G$ sedimentin yoğunluğunun suyun yoğunluğuna oranı

$E_{z}$ ve $D_{c}$ sırası ile tabandan ayrılan ve tabana çökelen katı madde

$n$ üçgen olarak geliştirilmiş olan ağların dik birim dış vektörü

$d_{l}$ üçgen olarak geliştirilmiş olan ağların birim kenar uzunluğu

$d_{W}$ üçgen olarak geliştirilmiş olan ağların alanı

$\Omega$ üçgen olarak geliştirilmiş olan ağların kontrol hacmi

$F$ normal akı vektörü

$A$, ağlarda oluşturulmuş her bir hücrenin alanı

$m$ kenar sayıs

$L_{m}$ her bir hücrenin kenar uzunlukları

$T(\varnothing)$ ile $T(\varnothing)^{-1}$ sirası ile dönüşüm ile ters dönüşüm matrisleri

$\forall_{i} \forall_{p}, \forall_{E}$ sırası ile kontrol hacminin yüzeyindeki, merkez ve sağ noktanın değeri

$r$ ise değeri menba yüzeyindeki değişimin mansap yüzeyindeki değişime oranı

$P, E$ ile $W$ sırası ile hesap noktasının merkezi, sağ ile solundaki noktaları

$U$ ile $D$ sirası ile memba ile mansap noktalarını

\section{KAYNAKLAR}

[1] Kaya B, Gharehbaghi A. Modelling of sediment transport with Finite volume method under unsteady conditions, Journal of the Faculty of Engineering and Architecture of Gazi University, Cilt.27, 2012, s.827-836.

[2] Fe J, Cueto-Felgueroso L, Navarrina F, Puertas J. Numerical viscosity reduction in the resolution of the shallow water equations with turbulent term, International Journal for Numerical Methods in Fluids, Cilt.58, 2008, s.781-802.

[3] Whipple K.X, Parker G, Paola C, Mohrig D. Channel Dynamics, Sediment Transport, and the Slope of Alluvial Fans: Experimental Study, The Journal of Geology, Cilt.106, 1998, s.677-693.

[4] Seo I.W, Jun I, Choi H.S. One-dimensional Finite Element Model for Suspended Sediment Transport Analysis, World City Water Forum, Cilt.24, 2009, s.3107-3112.

[5] Kaya B, Gharehbaghi A. Implicit solutions of advection diffusion equation by various numerical methods, Australian Journal of Basic and Applied Sciences, Cilt.8, 2014, s.381391.

[6] Bradford S.F, Sanders B. F. Finite-Volume Model for Shallow-Water Flooding of Arbitrary Topography, Journal of Hydraulic Engineering, Cilt.128, 2002, s.289-298. 
[7] Farsirotou E.D, Soulis J.V., Dermissis V.D. A Numerical Method for 2-D Bed Morphology Calculations, International Journal of Computational Fluid Dynamics, Cilt 16, 2002, s.187-200.

[8] Liu X, Landry B.J, García M.H. Two-dimensional scour simulations based on coupled model of shallow water equations and sediment transport on unstructured meshes, Coastal Engineering, Cilt.55, 2008, s.800-810.

[9] Castro Diaz M.J, Fernández-Nieto E.D, Ferreiro A.M, Parés C. Two-dimensional sediment transport models in shallow water equations. A second order finite volume approach on unstructured meshes, Computer Methods in Applied Mechanics and Engineering, Cilt.198, 2009, s.2520-2538.

[10] Kuang C.P, hang Y, Gu J, Pan Y, Huang J. A two-dimensional morphological model based on a next generation circulation solver I: Formulation and validation." Coastal Engineering, Cilt.59, 2011, s.1-13.

[11] Cea L, Vázquez-Cendón M.E. Unstructured finite volume discretisation of bed friction and convective flux in solute transport models linked to the shallow water equations, Journal of Computational Physics, Cilt.231, 2012, s.3317-3339.

[12] Wu W, Sanchez A, Zhang M. An implicit 2-d depth-averaged finite-volume model of flow and sediment transport in coastal waters, Journal of Coastal Research, Cilt.59, 2011 ,s.15-26.

[13] Gharehbaghi A, Kaya B. Modelling of two dimensional sediment transport phenomenon under unsteady conditions, DSI technical bulletin, Cilt.119, 2015, s.1-9.

[14] Abdelaziz S, Bui M.D, Rutschmann P. Numerical investigation of flow and sediment transport around a circular bridge pier, 34th IAHR World Congress, Balance and Uncertainty, Brisbane, Australia, 2011.

[15] Vasquez J, Hurtig K, Hughes B. Computational Fluid Dynamics (CFD) Modeling of Run-of-River Intakes, Hydrovision 2013 Conference Proceedings, Denver, 2013.

[16] Yulistiyanto B. Numerical modeling on shallow water $2 \mathrm{~d}$ equations applied on flow around a cylinder, proceeding of The 6th International Conference on Numerical Analysis in Engineering, Lombok Island, Mataram City, West Nusa Tenggara Province INDONESIA, 2009.

[17] Tayfur G, Singh P. Kinematic wave model for transient bed profiles in alluvial channels under nonequilibrium conditions. Water Resources Research, Cilt.43, 2007, s.111.

[18] Meyer-Peter E, Müller R. Formulas for bed load transport, International Association of Hydraulic Research, IAHR. 1948, s.39-64.

[19] Chien N. The present status of research on sediment transport, Transactions of the American Society of Civil Engineers, Cilt.121, 1956, s.833-868.

[20] Yang C.T. Sediment Transport Theory and Practice, New York:McGraw-Hill, 1996.

[21] Anastasiou k, Chan C.T. Solutin of the $2 \mathrm{~d}$ shallow water equations using the finite volume method on unstructured triangular meshes, International journal for numerical methods in fluids, Cilt.24, 1997 ,s.1225-1245.

[22] Wu W, Wang P, Chiba N. Comparison of Five Depth-Averaged 2-D Turbulence Models for River Flows, Archives of Hydro-Engineering and Environmental Mechanics, Cilt.51, 2004, s.183-200.

[23] Yafei J, Wang, S.S.Y. CCHE2D: Two-dimensional Hydrodynamic and Sediment Transport Model For Unsteady Open Channel Flows Over Loose Bed, Technical Report No. NCCHE-TR-2001-1, 2001.

[24] Versteeg H.K, Malalasekera W. An introduction to computational fluid, Glasgow: Bell \& Bain Limited, 2007. 


\section{ÖZGECMMis / CV}

Amin GHAREHBAGHI, Dr.

Lisans derecesini 2009'de İranın Urmia Üniversitesi Su Mühendisliği Bölümü’nden aldı. Yüksek Lisans derecesini 2011'de Dokuz Eylül Üniversitesi İnşaat Mühendisliği Bölümü'nden aldı. Doktora derecesini 2015'de Dokuz Eylül Üniversitesi İnşaat Mühendisliği'nden aldı. Temel ilgi alanları Serbest Yüzeyle akışkanlar, Boru şebekeleri hidroliği, Hidrolik alanında saysal modelleme (FDM, FVM, DQM), Açık kanallarda ve ırmaklarda katı madde taşınımı hereketinin incelenmesi, Yeraltı suları, Hidrolik yapıların tasarımı, Uygulamalı hidrodinamik, Hidrolik mühendisliği, Çevresel akışkanlar mekaniği üzerinedir.

He got his Bachelor's degree in Water Engineering Department at Urmia University, Urmia/Iran in 2009. His master degree is in the civil engineering department of Dokuz Eylül University, Izmir/Turkey in 1992. He got a PhD degree in Civil Engineering Department at Dokuz Eylül University in 2015. His major areas of interests are: Free surface transient flows, Hydraulics of pipeline systems, Numerical modelling in hydraulics (FDM, FVM, DQM), Sediment transport phenomenon in rivers and open channels, Groundwater, Design of hydraulic structures, Applied hydrodynamics, Hydraulic engineering, Environmental fluid mechanics.

\section{Birol KAYA; Doç.Dr. (Assoc.Prof)}

Lisans derecesini 1984'de Dokuz Eylül Üniversite İnşaat Mühendisliği Bölümü'nden, Yüksek Lisans derecesini 1987'de Dokuz Eylül Üniversitesi Fen Bilimleri Enstitüsü İnşaat Mühendisliği Anabilim Dalı'ndan, Doktora derecesini 1993 yılında Dokuz Eylül Üniversitesi Fen Bilimleri Enstitüsü İnşaat Mühendisliği Anabilim Dalı'ndan aldı. Halen Dokuz Eylül Üniversitesi İnşaat Mühendisliği Bölümü'nde öğretim üyesi olarak görev yapmaktadır. Temel çalışma alanları: Serbest Yüzeyli Akımlar, Basınçlı Akımlar, Sayısal Modelleme, Sediment Taşınımı, Tarihi Su Yapıları üzerinedir.

He got his bachelors' degree in the Civil Engineering Department at Dokuz Eylul Uniiversity in 1984, his master degree in the Graduate School of Natural and Applied Sciences Civil Engineering Division at Dokuz Eylül University in 1987, PhD degree in the Graduate School of Natural and Applied Sciences Civil Engineering Division at Dokuz Eylül University in 1993. He is still an academic member of the Civil Engineering Department at Dokuz Eylül University. His major areas of interests are: Free Surface Flows, Pressurized Flows, Numerical Modelling, Sediment Transport, Ancients Waterworks. 